\title{
HYPOCALCAEMIA DUE TO PHOTOTHERAPY IN TERM NEONATES WITH NEONATAL HYPERBILIRUBINEMIA
}

\author{
Mohammed Yahya Padippura1, Darly Saramma Mammen², Jayaprakash Parameswaran ${ }^{3}$, Suresh Sebastian Vadakkedam ${ }^{4}$
}

1 Junior Resident, Department of Paediatrics, Government Medical College, Kottayam, Kerala, India.

${ }_{2}^{2}$ Associate Professor, Department of Paediatrics, Government Medical College, Kottayam, Kerala, India.

${ }^{3}$ Assistant Professor, Department of Paediatrics, Government Medical College, Kottayam, Kerala, India.

${ }^{4}$ Assistant Professor, Department of Paediatrics, Government Medical College, Kottayam, Kerala, India.

ABSTRACT

\section{BACKGROUND}

Jaundice is an important problem in the first week of life.1,2 It is a cause for concern for the physician and a source of anxiety for the parents. High bilirubin level may be toxic to the developing central nervous system and may cause neurological impairment even in term newborns. ${ }^{3}$ Jaundice in newborn is quite common affecting nearly $60 \%$ of term and $80 \%$ of preterm neonates during first week of life.

The objective of this study was to evaluate the incidence of hypocalcaemia due to phototherapy in term neonates, and symptomatic hypocalcaemia due to phototherapy.

\section{MATERIALS AND METHODS}

A prospective study conducted at Special Care Newborn Unit in Govt. Medical College, Kottayam. All term neonates AGA admitted for phototherapy were taken consecutively till the estimated sample size of 165 was achieved according to the inclusion and exclusion criteria. The data was obtained in a prestructured proforma. Blood samples were taken before starting phototherapy and after $48 \mathrm{hrs}$ of phototherapy. Serum calcium was estimated by colorimetric method using dye Arsenazo III by AutoZyme Calcium Arsenazo III. Neonates were observed for symptoms of hypocalcaemia, and other adverse effects of phototherapy. The change in calcium level, incidence of hypocalcaemia, and symptoms of hypocalcaemia and observed adverse effects were analysed statistically.

\begin{abstract}
RESULTS
165 term babies meeting the inclusion and exclusion criteria were studied. 51.5\% were male $48.5 \%$ were female babies. $71.5 \%$ were born by normal delivery and $28.5 \%$ were born by CS. Mean birth weight of babies were $3.02 \mathrm{~kg}$. Before phototherapy, there was no statistically significant difference in calcium values between any of the groups. Statistically significant fall in serum calcium level following phototherapy was observed in the study with a p value of 0.003 . Incidence of hypocalcaemia following phototherapy was found to be $26.1 \%$. Symptomatic hypocalcaemia following phototherapy was found to be only $1.2 \%$.
\end{abstract}

\section{CONCLUSION}

This study shows that phototherapy causes significant fall in serum calcium level. Incidence of hypocalcaemia due to phototherapy was found to be $26.1 \%$. So, close monitoring of serum calcium level is warranted for babies receiving phototherapy and routine supplementation of calcium should be considered in them.

\section{KEY WORDS}

Hypocalcaemia, Neonatal Hyperbilirubinemia, Phototherapy.

HOW TO CITE THIS ARTICLE: Padippura MY, Mammen DS, Parameswaran J, et al. Hypocalcaemia due to phototherapy in term neonates with neonatal hyperbilirubinemia. J. Evolution Med. Dent. Sci. 2018;7(48):5207-5211, DOI: 10.14260/jemds/2018/1155

\section{BACKGROUND}

Jaundice is an important problem in the first week of life.1,2 It is a cause of concern for the physician and a source of anxiety for the parents. High bilirubin level may be toxic to the developing central nervous system and may cause neurological impairment even in term newborns. ${ }^{3}$ Jaundice in newborn is quite common affecting nearly $60 \%$ of term and $80 \%$ of preterm neonates during first week of life. 4

'Financial or Other Competing Interest': None.

Submission 09-08-2018, Peer Review 07-11-2018,

Acceptance 13-11-2018, Published 26-11-2018.

Corresponding Author:

Darly Saramma Mammen,

Associate Professor,

Department of Paediatrics,

Institute of Child Health, Government Medical College,

Kottayam-686561, Kerala, India.

E-mail: drdarlymammen@gmail.com

DOI: $10.14260 /$ jemds/2018/1155
Jaundice is attributable to physiological immaturity of neonates to handle increased bilirubin production. ${ }^{1}$

Visible jaundice usually appears between 24-72 hours of age. Basic pathophysiology of jaundice is same in term and preterm neonates, but premature babies are at a higher risk of developing hyperbilirubinemia. In most of cases, it is benign, and no intervention is required. Approximately 5$10 \%$ of them have clinically significant hyperbilirubinemia.5,6

Phototherapy is an important modality of treatment used for management of neonatal hyperbilirubinemia.7,8 Hypocalcaemia is a lesser known but potential complication of phototherapy. ${ }^{9}$ Hypocalcaemia can cause seizures, cardiac arrhythmias, lethargy, abdominal distension, poor feeding etc. Romagnoli et al (1979) for the first time suggested the association of hypocalcaemia with phototherapy in preterm newborns. ${ }^{10}$ Inhibition of pineal gland via transcranial illumination, results in decline of melatonin secretion; which 
blocks the effect of cortisol on calcium level. This hypocalcemic effect could be blunted by covering the head. ${ }^{11}$

\section{MATERIALS AND METHODS}

This was a prospective single center study designed to evaluate the incidence of hypocalcaemia due to phototherapy in term neonates and also the incidence of symptomatic hypocalcaemia due to phototherapy.

\section{Sample Size was Calculated by the Formula}

$\mathrm{N}=\mathrm{Z}^{2} 1-\propto / 2 \times \mathrm{p} \times \mathrm{q} / \mathrm{d}^{2}$

$\mathrm{Z} \alpha=1.96$ for $\alpha$ at $5 \%$ level of significance

$\mathrm{P} \quad=$ Anticipated population proportion of factor under study, taken as 40 according to previous studies.

$\mathrm{q} \quad=1-\mathrm{p}$

$\mathrm{d} \quad=$ Relative precision 20

Chance of drop out from study $\quad=$ taken as 15

$\mathrm{N} \quad=165$ where $\mathrm{p}=40$

All term neonates of adequate for gestational age (AGA) admitted for phototherapy were taken consecutively till the estimated sample size of 165 was achieved according to inclusion and exclusion criteria.

Term neonates of AGA receiving phototherapy for unconjugated hyperbilirubinemia without any comorbidities like birth asphyxia, septicaemia and renal failure were included in the study.

Neonates with conjugated hyperbilirubinemia, comorbidities like birth asphyxia, septicaemia, renal failure, preterm babies, small for gestational age, babies with intravenous fluids and intravenous medications and infant of diabetic mothers were excluded from the study.

Written informed consent was obtained from parents or legal guardian before being enrolled for the study. A complete history and thorough physical examination were done, and relevant investigations were carried out. The data was obtained in a prestructured proforma. Blood samples were taken before starting phototherapy and after 48 hours of phototherapy. Serum calcium was estimated by colorimetric method using dye Arsenazo III by Autozyme Calcium Arsenazo III. Neonates were observed for symptoms of hypocalcaemia, i.e. jitteriness, seizures, abdominal distension, hypotonia, poor feeding and other adverse effects of phototherapy. The change in calcium level, incidence of hypocalcaemia, symptoms of hypocalcaemia and observed adverse effects of phototherapy were analysed statistically.

\section{Data Analysis}

Data was tabulated in Microsoft Excel and statistical evaluation was performed using the Statistical Package for the Social Sciences (SPSS) 22 for windows programme. Descriptive statistics were used to describe the results. The results were analysed by one-way ANOVA test and independent sample $t$ test. The resulting $p$ value $<0.05$ were considered significant.

\section{RESULTS}

Total number of neonates 165. 85(51.5\%) were boy and $80(48.5 \%)$ were girl babies.

$118(71.5 \%)$ were born by normal vaginal delivery and $47(28.5 \%)$ were born by caesarean section.
All were term babies with 37 completed weeks. Of the 165 babies 13 (7.9\%) between 37 weeks to 37 weeks 6 days, 54 (32\%) babies were between 38 weeks to 38 weeks 6 days, $79(47.9 \%)$ babies between 39 weeks to 39 weeks 6 days and $19(11.5 \%)$ babies 40 weeks completed or above.

For 15 cases (9.1\%) phototherapy was started with in 24 hrs. of birth, phototherapy was started between $25 \mathrm{hrs}$. to 48 hrs for 48 (29.1\%) cases, between 49 hrs. to $72 \mathrm{hrs}$. for $89(53.9 \%)$ cases, and between $73 \mathrm{hrs}$ to $96 \mathrm{hrs}$ for $13(7.9 \%)$ cases

Of the 165 cases 81 (49.1\%) had no major blood group incompatibility (i.e. neither $\mathrm{ABO}$ nor $\mathrm{Rh}$ blood group incompatibility) between baby and mother, this group were called as no incompatibility group. 47 (28.5\%) cases belonged to $\mathrm{OA}$ incompatibility group, $24(14.5 \%)$ of cases belonged to OB incompatibility group and 13 (7.9\%) cases $\mathrm{Rh}$ blood group incompatibility.

\begin{tabular}{|c|c|c|c|}
\hline Age Group & Number & $\begin{array}{c}\text { Mean Calcium Before } \\
\text { Phototherapy }\end{array}$ & $\begin{array}{c}\text { Standard } \\
\text { Deviation }\end{array}$ \\
\hline 0- $24 \mathrm{hrs}$ & 15 & 9.600000 & .5830952 \\
\hline 25- $48 \mathrm{hrs}$ & 48 & 9.616667 & .6682251 \\
\hline $49-72 \mathrm{hrs}$ & 89 & 9.534831 & .6326533 \\
\hline $73-96 \mathrm{hrs}$ & 13 & 9.492308 & .6473813 \\
\hline Overall & 165 & 9.561212 & .6357814 \\
\hline
\end{tabular}

Table 1. Mean Calcium Level before Starting Phototherapy at Various Ages of Birth in the Study Group

Table shows mean calcium levels before starting phototherapy, and categorized according to the age before starting phototherapy. Of the 165 cases phototherapy were started before completing 24 hrs. since birth in 15 cases and mean calcium value in these babies were 9.6000. For those babies for whom phototherapy started between 25-48 hrs mean calcium value before starting phototherapy was 9.6166 . For those babies for whom phototherapy started between 49 $72 \mathrm{hrs}$ mean calcium value before starting phototherapy was 9.5348. For those babies for whom phototherapy started between 72-96 hrs mean calcium value before starting phototherapy was 9.4923. For those babies for whom phototherapy started after hrs of life mean calcium value before starting phototherapy was 9.5612 . The results were analysed using one-way ANOVA test. F value was found to be 0.239 and $p$ value 0.869 , since $p$ value was more than 0.05 this difference was statistically insignificant.

\begin{tabular}{|c|c|c|c|}
\hline Incompatibility & $\begin{array}{c}\text { Mean Calcium } \\
\text { Before } \\
\text { Phototherapy }\end{array}$ & Number & $\begin{array}{c}\text { Standard } \\
\text { Deviation }\end{array}$ \\
\hline NI & 9.553086 & 81 & .6528948 \\
\hline OAI & 9.561702 & 47 & .5712508 \\
\hline OBI & 9.608333 & 24 & .6184951 \\
\hline RHI & 9.523077 & 13 & .8318191 \\
\hline \multicolumn{3}{|c|}{ Table 2. Mean Calcium Level before Starting } \\
Phototherapy in Various Incompatibility Group \\
\hline
\end{tabular}

Table shows mean serum calcium level before phototherapy in various incompatibility group. Mean and standard deviation of serum calcium before phototherapy in no incompatibility group were 9.5530 and 0.6529 respectively. Mean and standard deviation of serum calcium before phototherapy in OA incompatibility group were 9.5617 and 0.5712 respectively. Mean and standard deviation 
of serum calcium before phototherapy in $\mathrm{OB}$ incompatibility group were 9.6083 and 0.6185 respectively. Mean and standard deviation of serum calcium before phototherapy in RH incompatibility group were 9.5231 and 0.8318 respectively. The results were analysed using one-way ANOVA test. F value was found to be 0.063 and $p$ value 0.979 , since $\mathrm{p}$ value was more than 0.05 this difference was statistically insignificant.

\begin{tabular}{|c|c|c|c|}
\hline Sex & Mean & N & Std. Deviation \\
\hline Male & 9.585882 & 85 & .6544996 \\
\hline Female & 9.535000 & 80 & .6183072 \\
\hline Total & $\mathbf{9 . 5 6 1 2 1 2}$ & $\mathbf{1 6 5}$ & $\mathbf{. 6 3 5 7 8 1 4}$ \\
\hline Table 3. Mean Calcium Level before Starting \\
Phototherapy According to Sex
\end{tabular}

Table shows mean calcium level before starting phototherapy in male babies and female babies. Mean and standard deviation of serum calcium level before starting phototherapy in male babies were 9.5859 and 0.6545 respectively, and in female babies 9.5350 and. 6183 respectively. The results were analysed using independent samples t-test. $t$ value was found to be 0.513 and $p$ value 0.73 , since $p$ value was more than 0.05 this difference was statistically insignificant.

\begin{tabular}{|c|c|c|c|}
\hline Mode of Birth & Mean & $\mathbf{N}$ & $\begin{array}{c}\text { Std. } \\
\text { Deviation }\end{array}$ \\
\hline Normal Delivery & 9.531356 & 118 & .5904799 \\
\hline Caesarean Section & 9.636170 & 47 & .7391021 \\
\hline Total & $\mathbf{9 . 5 6 1 2 1 2}$ & $\mathbf{1 6 5}$ & $\mathbf{. 6 3 5 7 8 1 4}$ \\
\hline $\begin{array}{c}\text { Table 6. Mean Calcium Level before Starting } \\
\text { Phototherapy Grouped According to Mode of Birth }\end{array}$ \\
\hline
\end{tabular}

Table shows mean calcium level before starting phototherapy in babies born by normal delivery and caesarean section. Mean and standard deviation of serum calcium level before starting phototherapy in babies born by normal delivery were 9.5314 and. 5905 respectively, in babies born by caesarean section 9.5612 and 0.6357 respectively. The results were analysed using independent samples t-test. $t$ value was found to be 0.956 and $p$ value 0.341 , since $p$ value was more than 0.05 this difference was statistically insignificant.

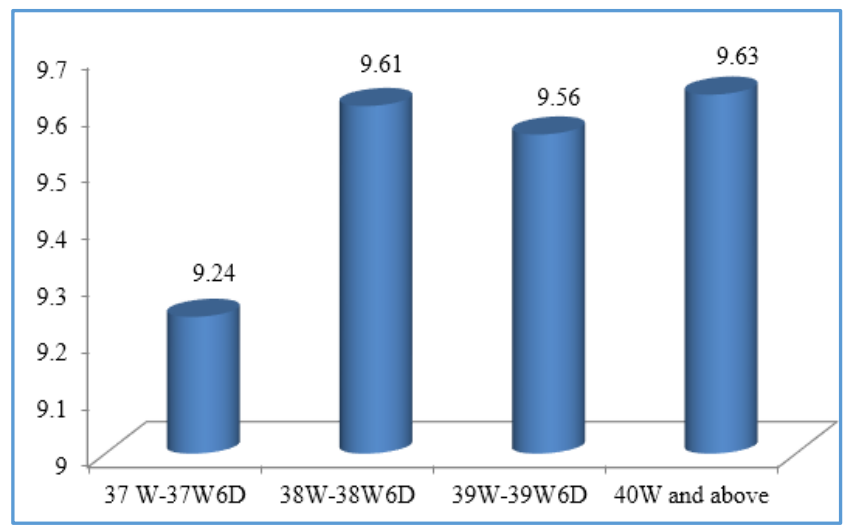

Figure 4. Mean Calcium Level before Starting Phototherapy in Various Gestational Age Groups in the Study Population
Figure shows mean serum calcium level before phototherapy in babies with different gestational ages at birth. Mean and standard deviation of serum calcium before phototherapy in babies born between 37W-37W6D were 9.2385 and 0.5966 respectively. Mean and standard deviation of serum calcium before phototherapy in babies born between 38W-38W6D were 9.6129 and 0.7209 respectively. Mean and standard deviation of serum calcium before phototherapy in babies born between 39W-39W6D were 9.5620 and 0.5403 respectively. Mean and standard deviation of serum calcium before phototherapy in babies born between 40 Weeks and more were 9.6316 and 0.7499 respectively. The results were analysed using one-way ANOVA test. F value was found to be 1.321 and $p$ value 0.269 ; since $\mathrm{p}$ value was more than 0.05 this difference was statistically insignificant.

Mean and standard deviation of birth weight in male babies were 3.0404 and 0.3063 respectively and in female babies 3.0136 and 0.3067 respectively. Results were analysed using independent sample t-test, t-value was found to be 0.560 and $p$ value 0.576 . Since $p$ value is more than 0.05 , this difference was found to be statistically insignificant.

Mean and standard deviation of birth weight in babies born by normal delivery were 3.0658 and 0.2928 respectively and in babies born by CS 2.9311 and 0.3197 respectively. Results were analysed using independent sample t-test, tvalue was found to be 2.59 and $p$ value 0.14 . Since $p$ value is more than 0.05 , this difference was found to be statistically insignificant.

Mean and standard deviation of serum total bilirubin level before starting phototherapy in male babies were 17.0668 and 2.2615 respectively, in female babies were 17.0939 and 2.1062. The results were analysed using independent samples t-test. $t$ value was found to be 0.079 and $\mathrm{p}$ value 0.6780 , hence $\mathrm{p}$ is $>.05$ this difference is statically insignificant.

\section{DISCUSSION}

This study was conducted with an aim to find out the incidence of hypocalcaemia due to phototherapy in term neonates, incidence of symptomatic hypocalcaemia due to phototherapy and other adverse effects of phototherapy.

This prospective study was conducted in term neonates, i.e. born after 37 weeks gestation completed, appropriate for gestational age, i.e. birth weight $>/=2500$ grams.

There were total 165 babies in this study. 85 (51.5\%) were male and $80(48.5 \%)$ were female babies. There is a slight male preponderance in this study. 118 (71.5\%) babies were born by normal vaginal delivery and 47 (48.5\%) were born by CS (Caesarean section).

13 cases (7.9\%) were born at a gestational age (GA) between 37 weeks to 37 week 6 days, 54(32.7\%) cases were born at gestational age between 38 weeks to 38 weeks 6 days, $79(47.9 \%)$ of cases were born at gestational age between 39 weeks to 39 week 6 days and 19 (11.5\%) of cases were born 40 week completed gestation.

Among the 165 babies 81 (41\%) of babies had no blood group incompatibility with mother, $47(28.5 \%)$ of babies has OA incompatibility with mother, $24(14.5 \%)$ cases had OB incompatibility with mother and 13 (7.9\%) babies had $\mathrm{Rh}$ blood group incompatibility with mother. 
Among the 165 babies 15 (9.1\%) babies had started on phototherapy within $1^{\text {st }} 24$ hrs of life. These include 2 babies with no incompatibility, 9 babies with OA incompatibility, 1 baby with $\mathrm{OB}$ incompatibility and 3 babies with $\mathrm{RH}$ incompatibility. For $48(29.1 \%)$ babies phototherapy was started between 25 to $48 \mathrm{hrs}$ of life, of which 20 babies were with no incompatibility, 16 babies were with $\mathrm{OA}$ incompatibility, 9 babies were with OB incompatibility and 3 babies were with RH incompatibility. For 89 (53.9\%) babies phototherapy was started between 49 to $76 \mathrm{hrs}$ of life, of which 50 babies were with no incompatibility, 20 babies were with $\mathrm{OA}$ incompatibility, 14 babies were with $\mathrm{OB}$ incompatibility and 5 babies were with RH incompatibility. For $13(7.9 \%)$ babies phototherapy was started between 73 to $96 \mathrm{hrs}$ of life, of which 10 babies were with no incompatibility, 2 babies were with $\mathrm{OA}$ incompatibility, 1 baby was with RH incompatibility.

Mean and standard deviation of birth weights of male babies were 3.0403 and 0.3063 respectively and in female babies were 3.0236 and 0.3067 respectively. The results we0re analysed using independent samples T-test. $t$ value was found to be 0.560 and p value was found to be 0.576 . Since $\mathrm{p}$ value was $>.05$ this difference was statistically insignificant.

Mean and standard deviation of birth weights in babies born by normal delivery were 3.065 and 0.2928 respectively and in babies born by CS were 2.9311 and 0.3796 respectively. The results were analysed using independent samples T-test. $t$ value was found to be 1.780 and $p$ value was found to be .077 . Since $p$ value was $>.05$ this difference was statistically insignificant.

Mean and standard deviation of birth weights in babies no blood group incompatibility with mother were 3.0137 and 0.3272 respectively, in babies with $\mathrm{OA}$ incompatibility were 3.0521 and 0.2817 respectively, in babies with OB incompatibility were 3.0971 and 0.3219 respectively and in babies with RH incompatibility were 2.8946 and 0.1713 respectively. The results were analysed using one-way ANOVA test. F value was found to be 1.399 and $p$ value was found to be 0.245 , since $p$ value was $>.05$ this difference was statistically insignificant.

Mean and standard deviation serum calcium level before phototherapy in male babies were 9.5859 and 0.6545 respectively and in female babies were 9.5350 and 0.6183 respectively. The results were analysed using independent samples T-test. $t$ value was found to be 0.513 and $p$ value was found to be 0.736 . Since $p$ value was $>.05$ this difference was statistically insignificant.

Mean and standard deviation of serum calcium level before phototherapy in babies born by normal delivery were 9.5314 and 0.5905 respectively and in babies born by CS were 9.6362 and 0.7391 respectively. The results were analysed using independent samples T-test. $t$ value was found to be 0.956 and $p$ value was found to be 0.341 . Since $p$ value was $>.05$ this difference was statistically insignificant.

Mean and standard deviation of birth of serum calcium level before phototherapy in babies no blood group incompatibility with mother were 9.5531 and 0.6529 respectively, in babies with OA incompatibility were 9.5617 and 0.5713 respectively, in babies with $\mathrm{OB}$ incompatibility were 9.6083 and 0.6185 respectively and in babies with $\mathrm{RH}$ incompatibility were 9.5231 and 0.8318 respectively. The results were analysed using one-way ANOVA test. F value was found to be 0.063 and $p$ value 0.979 , since $p$ value was $>.05$ this difference was statistically insignificant.

Mean and standard deviation of serum calcium level before phototherapy in babies born at GA between 37 week to 37 week 6 days were 9.2385 and 0.5966 respectively, in babies born at GA between 38 week to 38 week 6 days were 9.6130 and 0.7209 respectively, in babies born at GA between 39 week to 39 week 6 days were 9.5620 and 0.5403 respectively and in babies born at GA 40 weeks and more were 9.6316 and 0.7499 respectively. The results were analysed using one-way ANOVA test. F value was found to be 1.321 and $p$ value 0.269 , since $p$ value was $>.05$ this difference was statistically insignificant.

Mean and standard deviation of serum calcium level before phototherapy in babies with phototherapy started in $1^{\text {st }} 24$ hrs of life were 9.600 and 0.5831 respectively, in babies with phototherapy started between 25 to 48 hrs were 9.6167 and 0.6682 respectively, in babies with phototherapy started between 49 to 72 hrs were 9.5348 and 0.6327 respectively and in babies with phototherapy started between 73 to 96 hrs were 9.4923 and 0.6474 respectively. The results were analysed using one-way ANOVA test. F value was found to be 0.239 and $p$ value 0.869 , since $p$ value was $>.05$ this difference was statistically insignificant.

Mean and standard deviation total serum bilirubin (TSB) before phototherapy in male babies were 17.0668 and 0.2453 respectively and in female babies were 17.0939 and 0.2355 respectively. The results were analysed using independent samples T-test. $t$ value was found to be 0.079 and $p$ value was found to be 0.678 . Since $p$ value was $>.05$ this difference was statistically insignificant.

Mean and standard deviation of TSB before phototherapy in babies born by normal delivery were 17.3259 and 2.0654 respectively and in babies born by CS were 16.1324 and 2.3811 respectively. The results were analysed using independent samples T-test. $\mathrm{t}$ value was found to be 2.907 and $p$ value was found to be 0.417 . Since $p$ value was $>.05$ this difference was statistically insignificant.

In the study population mean and standard deviation of serum calcium levels before starting phototherapy were 9.5612 and 0.0494 respectively and after 48 hrs of phototherapy were 8.3300 and 0.0468 respectively. The result was analysed by using paired sample t-test. $t$ value was found to be 20.614 and $p$ value 0.003 . Since $p$ value was less than 0.05 , this difference was statistically significant.

Among the 165 babies included in the study population, none of the babies had hypocalcaemia before starting phototherapy. After $48 \mathrm{hrs}$ of phototherapy 43 babies (26.1\%) developed hypocalcaemia. Among those who developed hypocalcaemia only 2 developed symptoms of hypocalcaemia. Symptom developed these two cases were jitteriness. No other hypocalcemic symptoms were observed in babies who developed hypocalcaemia following phototherapy. Jitteriness was noticed in 5 babies without hypocalcaemia. In this study adverse effects noticed following phototherapy were skin discolourations, loose stool, hyperthermia, and rashes. 35(21.2\%) of cases developed skin discolourations, loose stool was seen in $6(3.6 \%)$ of case, rashes were seen in $15(9.1 \%)$ of cases and hyperthermia were seen in $25(15.2 \%)$ of cases. Incidence of hypocalcaemia due to phototherapy in the present study was $26.1 \%$ and 
incidence of symptomatic hypocalcaemia due to phototherapy was $1.2 \%$.

\section{Limitations of the Study}

There were no controls in this study. Controls with comparable physical and clinical parameters not receiving phototherapy would have taken and studied showing no fall in serum calcium compared to the phototherapy given group. That would have given more strength to this study.

For detecting true hypocalcaemia, ionized calcium level should be estimated. Because of economic concerns, this study estimated only serum calcium level. Estimation of serum calcium level could be affected by serum albumin level. The unbound ionized calcium is responsible for physiological activity of calcium. Those with hypoalbuminemia may show low serum calcium, with normal ionized calcium, without any hypocalcemic manifestation. This study didn't consider serum albumin level also. Hypocalcaemia was observed in $26.1 \%$ of cases in this study but symptomatic hypocalcaemia was only $1.2 \%$. Many of these cases may not have had true hypocalcaemia if serum albumin was accounted or ionized calcium level was estimated.

\section{CONCLUSION}

This study was done to find out the incidence of hypocalcaemia due to phototherapy in term neonates and incidence of symptomatic hypocalcaemia. Incidence of hypocalcaemia was found to be $26.1 \%$. The fall in serum calcium following phototherapy was statistically significant with a $\mathrm{p}$ value of 0.003 . Incidence of symptomatic hypocalcaemia was found to be $1.2 \%$. Following phototherapy $21.2 \%$ of cases developed skin discolourations, $9.1 \%$ of cases developed rashes and $15.2 \%$ of cases developed hyperthermia.

\section{REFERENCES}

[1] Ambalavanan N, Waldemar A, Carlo. Jaundice \& hyperbilirubinemia in the newborn: Kleigman $\mathrm{R}$, Stanton B, St. Geme S, eds. Nelson textbook of Pediatrics. 20th edn. Philadelphia: Elsevier 2016.
[2] Zahedpasha Y, Kacho AM, Lookzadeh M, et al. Effect of clofibrate on prolonged jaundice of term neonates. J Babol Univ Med Sci 2010;11(5):22-6.

[3] Boskabadi H, Maamouri G, Mafinejad S. The effect of traditional remedies (Camel's thorn, flixweed and sugar water) on idiopathic neonatal jaundice. Iran J Pediatr 2011;21(3):325-30.

[4] American Academy of Pediatrics Subcommittee on hyperbilirubinemia: clinical practice guideline: management of hyperbilirubinemia in the newborn infant 35 or more weeks of gestation. Pediatrics 2004;114(1):297-316.

[5] Maisels MJ, Gifford K, Antle CE, et al. Jaundice in the healthy newborn infant: a new approach to an old problem. Pediatrics 1988;81(4):505-11.

[6] Kiviahan C, James EJ. The natural history of neonatal jaundice. Pediatrics 1984;74(3):364-70.

[7] Wolff M, Schinasi DA, Lavelle J, et al. Management of neonates with hyperbilirubinemia: improving timeliness of care using a clinical pathway. Pediatrics 2012;130(6):e1688-e94.

[8] Porter ML, Dennis BL. Hyperbilirubinemia in the term newborn. Am Fam Physician 2002;65(4):599-606.

[9] Xiong T, Qu Y, Cambier S, et al. The side effects of phototherapy for neonatal jaundice: What do we know? What should we do? European Journal of Pediatrics 2011;170(10):1247-55.

[10] Romagnoli C, Polidori G, Cataldi L, et al. Phototherapyinduced hypocalcaemia. The Journal of Pediatrics 1979;94(5):815-6.

[11] Samane ZD, Minoo M. The effect of covering head on the hypocalcaemia caused by phototherapy in the icteric preterm infants in the Vali-e-Asr hospital in 2015: a randomized controlled trial. International Journal of Medical Research \& Health Sciences 2016;5,5(S):138-42. 